https://doi.org/10.48009/1_iis_2005_398-404

\title{
THE EFFECT OF PRIOR EXPOSURE TO PROJECT MANAGEMENT TECHNIQUES IN PROJECT-BASED COURSES
}

\author{
Manouchehr Tabatabaei, Georgia Southern University, mtabatab@georgiasouthern,edu \\ Han Reichgelt, Georgia Southern University, han@georgiasouthern.edu
}

\begin{abstract}
Project Management (PM) is an important component of baccalaureate programs in both Information Systems (IS) and Information Technology (IT). Many institutions offer a PM course in the curriculum, which students typically take in their last semester. However, other courses in IS and IT are often taught with a heavy emphasis on individual and group projects, and therefore it seems reasonable to expect that students would perform better in such courses if they had received formal instruction in PM earlier in their program of study. This paper is a pilot study to determine whether this is indeed the case. It compares the performance of students who had previously completed a PM course and students who had not in a heavily project-based database course.
\end{abstract}

Keywords: IS/IT Education, Project Management

\section{INTRODUCTION}

Project Management (PM) is an important component of undergraduate programs in Information Systems (IS) and Information Technology (IT). The IS 2002 Model Curriculum [7] contains a course on project management, and the ABET CAC draft accreditation criteria for programs in IT list the ability to assist in the creation of an effective project plan as one of the required skills for graduates from accredited IT programs [1].

Given the importance of PM for both IS and IT programs, the question naturally arises how to teach PM and at what stage. Many institutions offer a PM course, which students typically take as one of the last courses in their program of study. However, as we shall see in the next section, the concepts, tools, and techniques of PM can be beneficial to students earlier as they are often required to perform individual or team projects in many of their courses throughout the curriculum, and PM concepts permeate the IS 2002 Model Curriculum. If exposed to PM tools and concepts early on, students might apply them throughout their college careers. Practical examples such as planning one's program of study with Gantt charts can prepare students for more advanced projects and increase their appreciation of the tools and techniques of PM. It is, for instance, not uncommon for graduate students who have been exposed to PM concepts and software during their undergraduate studies to apply those tools for planning their graduate programs.

In this paper we address the question whether a course in PM does indeed help students perform better in courses that are heavily project-based. We report on a pilot study in which we compared the performance of students who had previously completed a course on PM in a database management course (DB), which was heavily project-based, to the performance of those who had not, and either took the PM course in a later semester or concurrently with the DB course. 


\section{PROJECT MANAGEMENT IN THE UNDERGRADUATE CURRICULUM}

PM is an integral part of the IS 2002 Model Curriculum. In the Model Curriculum, one of the two suggested final courses to wrap up an IS program is a course in PM. According to the Model Curriculum outline, the PM course should focus on "engaging in and completing a major system development project" [7, p. 32]. It is intended to meet the learning goals outlined in Table 1.

Table 1. Learning Unit Goals for IS 2002.10: Project Management and Practice

1. To ensure skills needed to design a project development and implementation plan;

2. To further develop and practice essential project management skills;

3. To develop skill in use of project management tools and methods within the context of an information systems project;

4. To select the proper project management tools and demonstrate their use;

5. To initiate, design, implement and discuss project close down;

6. To determine and analyze a significant problem using the systems approach to problem solving;

7. To develop requirements and specifications for multi-use information systems based on a database;

8. To present and explain the evolving leadership role of information management in organizations

9. To examine the process for development of information systems policies, procedures and standards in the organizations;

10. To discuss outsourcing and alternative implementations of the IS functions;

11. To discuss management of time and interpersonal relations.

Many programs in IS follow the IS 2002 Model Curriculum recommendations and offer a PM course as one of the final courses in an IS program.

However, a careful analysis of the Model Curriculum, as provided by Reif and Mitri [8], suggests that PM components are featured throughout the courses in the Model Curriculum. Thus, Reif and Mitri [8] argue that the 11 learning goals of the PM course in the IS 2002 Model Curriculum feature in many of the previous courses. Table 2, which is an expanded version of a similar table [8] in which the 1997 IS model curriculum is analyzed [3], shows how each learning goal features in the courses in the IS 2002 Model Curriculum. The numbers refers to the learning goals of the IS2002.10 - Project Management and Practice Model Course. 
Table 2. The Pervasiveness of PM in the IS 2002 Model Curriculum (adapted from [8]).

IS2002.P0

$\begin{array}{lllllllllll}1 & 2 & 3 & 4 & 5 & 6 & 7 & 8 & 9 & 10 & 11\end{array}$

Personal Productivity with IS technology

\begin{tabular}{lllll}
\hline IS2001.1 & $X$ & $X$ & $X$ & $X$
\end{tabular}

Fundamentals of Information Systems

IS2002.2

$\mathrm{X} \quad \mathrm{X}$

Electronic Business Strategy, Architecture and Design

IS2002.3

$\mathrm{X}$

$\mathrm{X} \quad \mathrm{X} \quad \mathrm{X}$

Information Systems Theory and Practice

IS2002.4

Information Technology Hardware \& System Software

IS2002.5

$\mathrm{X}$

Programming: Data, File and Object Structure

IS2002.6

Networks and Telecommunications

IS2002.7

$\mathrm{X}$

$\mathrm{X}$

$\mathrm{X}$

Analysis and Logical Design

\begin{tabular}{llllll}
\hline IS2002.8 & X & X & X & X & X
\end{tabular}

Physical Design and Implementation with DBMS

IS2002.9

$\begin{array}{lllll}X & X & X & X\end{array}$

Physical Design \& Implementation in Emerging

Environments

IS 2002.10

$\begin{array}{lllllllllll}X & X & X & X & X & X & X & X & X & X & X\end{array}$

Project Management and Practice

Based on the fact that facets of PM are included in many of the courses in the IS 2002 Model Curriculum one might consider offering an introductory PM course, which covers the theories of PM and gives students a chance to practice PM on a small scale, early in the curriculum.

Students might benefit from having a structured approach to problem solving early on and their coursework might improve if they knew how to structure team work and how to plan and execute projects on time. In addition, students would have the opportunity to practice PM skills throughout their college career and get a firmer grasp on the concepts, something which might benefit them in their careers later on [8]. PM skills are shown to decrease problems associated with many project failures in the field of IT, such as the inability to meet schedule and cost deadlines which often arise from communication and teamwork related issues. With roughly a trillion dollars spent on IT projects in the US alone per year, PM skills will only increase in importance $[8,2]$. 
Dunlap [5] makes a compelling argument in favor of including a capstone course offering students the opportunity to work on one real life project, as intended in the IS 2002 Model Curriculum PM course, as this will prepare students better for their career after graduation. However, Dunlap [5] also points out that if PM is covered in a senior level course, then students will not get the opportunity to apply material learned in core course until the end of their academic program and therefore suggests that students should be exposed to real life projects early on and that they should be given an opportunity to practice skills essentially taught in PM. Based on these indicators, it might be worthwhile to consider offering an Introduction to PM course focusing on the core and tools of PM early in the curriculum, thereby allowing students to gain an understanding of how to approach and tackle problems properly. An applied PM capstone course covering a real life client project could round off the curriculum (as intended by the model curriculum) [9]. This could be incorporated in a System Analysis and Design course, as in the IS program at NYU, or into an extended capstone project focusing on the development of a large IT application, as in the IT program at BYU Provo.

Clearly, the above leads to a distinct empirical question: Would students benefit from an early exposure to PM techniques in the sense that their performance in courses that are heavily projectbased would improve? We conducted a pilot study to start formulating an answer to this question. The next section provides a description of the experiment.

\section{METHODOLOGY}

We collected data on the performance of students enrolled in either a BBA IS program or a BS IT program at a comprehensive university in the South East in two courses, namely a PM course, and a DB course. Both the PM course and the DB course closely resemble the corresponding courses in the IS 2002 Model Curriculum. Thus, the PM course is an implementation of IS2002.10 - Project Management and Practice, while the DB course implements IS2002.8 Physical Design and Implementation with DBMS. Both courses have a Systems Analysis and Design course, which is itself an implementation of IS2002.07 - Analysis and Logical Design, as a prerequisite. In both semesters which were used for data collection (fall semester 2004 and spring semester 2005), the two courses were taught by the same instructors.

Both the PM course and the DB course are typically taken in the final semester of study by the BBA IS students. However, BS IT students often take the courses slightly earlier in their curriculum. Both courses are assessed by a combination of written exams and a set of group projects. In general, the group projects account for more than $60 \%$ of the final grade.

We collected data from four groups:

1. Students who completed the PM course in the fall semester of 2004 and the DB course in the spring semester of 2005 ;

2. Students who completed the DB course in the fall semester of 2004 and the PM course in the spring semester of 2005 ;

3. Students who completed the two courses simultaneously in the fall semester of 2004;

4. Students who completed the two courses simultaneously in the spring semester of 2005. 
We also collected cumulative GPAs for the students prior to taking the two courses in question, and determined whether they were juniors or seniors, as well as the major they were enrolled in. For each student, we also calculated a score to reflect their combined performance in both courses. In order to calculate the score, we assigned a numeric value to the letter grade received in the course $(\mathrm{A}=4$ to $\mathrm{F}=0)$. We ignored students who dropped either course before completion but we included students who failed either course. The total size of our sample was 79 students.

\section{RESULTS}

Table 3 presents the average cumulative GPA, the average combined score and the scores in the $\mathrm{DB}$ and the PM course respectively.

Table 3. Results on the Various DB and PM Courses

Group 1: Students who took PM before DB

Group 2: Students who took DB before PM

Group 3: Students who took DB and PM simultaneously in Fall 2004

Group 4: Students who took DB and PM simultaneously in Spring 2005

\begin{tabular}{lcccc} 
& $\begin{array}{c}\text { Average } \\
\text { Cumulative } \\
\text { GPA }\end{array}$ & $\begin{array}{c}\text { Average } \\
\text { combined score }\end{array}$ & $\begin{array}{c}\text { Average score } \\
\text { on the DB } \\
\text { course }\end{array}$ & $\begin{array}{c}\text { Average score } \\
\text { on the PM } \\
\text { course }\end{array}$ \\
\hline Group 1 $(\mathrm{n}=18)$ & 2.51 & 2.61 & 2.61 & 2.61 \\
Group 2 $(\mathrm{n}=15)$ & 2.70 & 2.40 & 2.60 & 2.20 \\
Group 3 $(\mathrm{n}=15)$ & 2.70 & 2.76 & 2.87 & 2.65 \\
Group 4 $(\mathrm{n}=31)$ & 2.72 & 2.84 & 3.06 & 2.58
\end{tabular}

Those who took PM first seem to have done better compared to those who took DB first, while those who took both courses simultaneously outperformed both other groups. This might be an indication that the two courses complement each other if the student can handle the workload and does not drop one of the two courses.

There were differences in the number of withdrawals between the different groups. Four students who attempted to take the DB and PM courses at the same time in the fall semester of 2004 withdrew from one of the courses ( 3 from the DB course and 1 from the PM course). In contrast, only 1 student withdrew from Group 4 and from Group 1 (in both cases from the DB course), and none from Group 2. Moreover, the students who withdrew typically did poorly in the course that they completed, and students who withdrew tended to have a low cumulative GPA. This suggests that reanalyzing the data by cumulative GPA might be beneficial. Table 4 reports the results.

As illustrated in Table 4, taking PM first has helped low GPA (<2.5) students more compared to higher GPA students $(\geq 2.5)$. In addition, it is clear that higher GPA students can do better taking both classes together, but low GPA students $(<2.5)$ are better off taking PM course first. The bracketed figures in the second column indicate the number of students in this category. 
Table 4. Breakdown of Results by Cumulative GPA

\begin{tabular}{llccc} 
Cumulative GPA & Average & $\begin{array}{c}\text { Average } \\
\text { Combined } \\
\text { Score }\end{array}$ & $\begin{array}{c}\text { Average } \\
\text { Score on DB } \\
\text { course }\end{array}$ & $\begin{array}{c}\text { Score on PM } \\
\text { course }\end{array}$ \\
\hline$\geq 3.0$ & Overall (26) & 3.32 & 3.40 & 3.22 \\
& Simultaneous (16) & 3.47 & 3.47 & 3.47 \\
& DB First (6) & 3.13 & 3.50 & 2.76 \\
$\geq 2.5,<3.0$ & 3.00 & 3.00 & 3.00 \\
& PM First (4) & & & \\
& Overall (19) & 2.68 & 3.00 & 2.37 \\
& Simultaneous (11) & 2.86 & 3.17 & 2.45 \\
& DB First (4) & 2.75 & 2.25 & 2.75 \\
& PM First (4) & 2.13 & 2.00 & 2.25 \\
& & & & \\
& Overall (35) & 2.13 & 2.11 & 2.15 \\
& Simultaneous (20) & 2.15 & 2.15 & 2.15 \\
& DB First (5) & 1.80 & 2.00 & 1.60 \\
& PM First (10) & 2.35 & 2.20 & 2.50
\end{tabular}

We also broke down the results by major, as illustrated in Table 5. The bracketed figures indicate number of students in the category.

Table 5. Breakdown of results by major

\begin{tabular}{llcccc} 
Major & & $\begin{array}{c}\text { Average } \\
\text { cumulative } \\
\text { GPA }\end{array}$ & $\begin{array}{c}\text { Average } \\
\text { Combined } \\
\text { Score }\end{array}$ & $\begin{array}{c}\text { Average } \\
\text { Score on } \\
\text { DB Course }\end{array}$ & $\begin{array}{c}\text { Average } \\
\text { Score on } \\
\text { PM Course }\end{array}$ \\
\hline IS & Overall (33) & 2.76 & 2.77 & 2.76 & 2.79 \\
& Simultaneous (27) & 2.77 & 2.85 & 2.81 & 2.89 \\
& DB First (4) & 2.94 & 2.50 & 2.75 & 2.25 \\
& PM First (2) & 2.12 & 2.25 & 2.0 & 2.50 \\
IT & & & & \\
& Overall (47) & 2.61 & 2.57 & 2.74 & 2.39 \\
& Simultaneous (20) & 2.60 & 2.61 & 2.89 & 2.32 \\
& DB First (11) & 2.71 & 2.36 & 2.55 & 2.18 \\
& PM First (16) & 2.56 & 2.66 & 2.69 & 2.62
\end{tabular}

As shown in Table 5, taking DB first has helped IS students more, but taking PM first has helped IT students more. Because of the courses they took prior to the DB and PM courses, IS students will tend to have a better business and management skills than IT students, who may have stronger technical skills. A PM course is broadly classified to address business/management and technical issues and therefore taking DB first may have helped the IS students acquire the relevant technical skills and taking PM first may have helped IT students acquire business and management skills. 


\section{DISCUSSION, LIMITATIONS, FUTURE WORK}

The results of this preliminary study indicate that students do benefit from PM knowledge for other courses, in this case a DB course. As the results indicate, students with a lower GPA benefit from having an understanding of PM tools to be applied to a heavily project-oriented course. Students with higher GPAs seem to apply concepts learned in either course to the respective other. Since both courses are modeled after the IS 2002 Model Curriculum, which suggests very heavy PM components in both those courses [7], the assumption that students benefit from exposure to PM core and tools seems to be supported as well.

With the importance of teamwork and project-based work growing in virtually every industry, PM skills will continue to be important for most college graduates [8]. Therefore, careful consideration on how and when to teach PM concepts is warranted, not just in the fields of IT and IS. Consequently, further research into the benefits of introducing PM concepts early on and on the best approach of doing so is called for. The present study merely presents preliminary findings. However, in the future, it will be replicated to include a larger sample of students at more than one institution. In addition, evaluation factors other than GPA alone will be taken into account. Students will be asked to evaluate the PM skill level at the beginning and end of the course. They will also be asked to keep a journal, indicating how taking the course has affected their handling of PM related tasks even outside the class room. In addition, the research conducted at the undergraduate level should be replicated at the graduate level [6]; [4].

\section{REFERENCES}

1. ABET. Criteria for Accrediting Computing Programs. Baltimore, MD., 2004. Available at http://www.abet.org/criteria_cac.html.

2. Capell, J. (2001). Entry Level IS Job Skills: A Survey of Employers, in: The Journal of Computer Information Systems, 42(2), 76-82.

3. Davis, G. (1997). IS '97. Model Curriculum and Guidelines for Undergraduate Degree Programs in Information Systems.

4. Du, S., Johnson, R. \& Keil, M. (2004). Project Management Courses in IS Graduate Programs: What is Being Taught? Journal of Information Systems Education, (15), 181-188.

5. Dunlap, J. (2005). Problem-Based Learning and Self-Efficacy: How a Capstone Course Prepares Students for a Profession. ETR\&D, 53(1), 65-85.

6. Gorgone, J. et. al. (1999). MSIS 2000 Model Curriculum and Guidelines for Graduate Degree Programs in Information Systems.

7. Gorgone, J. et. al. (2002). IS 2002 Model Curriculum and Guidelines for Undergraduate Degree Programs in Information Systems.

8. Reif, H. \& Mitri, M. (2005). Integration of Project Management Components in Undergraduate Information Systems Curricula, in: The Journal of Computer Information Systems, 45(3), 24-31.

9. Wirth, I. (1992). Project-Management Education: Current Issues and Future Trends, in: International Journal of Project Management, 10(1), 49-54. 